\title{
O nexo entre formalização e confiança na gestão da relação cliente-fornecedor
}

\author{
The nexus between formalization and trust in the \\ management of the client-supplier relation
}

\author{
Leonel Mazzali' \\ Celso Machado Junior ${ }^{2}$ \\ Cristiane Jaciara Furlaneto ${ }^{2}$
}

\begin{abstract}
Resumo: Na fase inicial da interação fornecedor-cliente, o grande desafio é a obtenção de um grau mínimo de confiança, suficiente para superar a barreira da ausência de conhecimento mútuo. Assim, o trabalho se volta para a discussão das formas de atuação sobre o comportamento dos agentes, tendo como foco o "aprender a cooperar". O objetivo é avaliar o efeito dos mecanismos formais de controle para a geração de um ambiente favorável à emergência da confiança. É um estudo explanatório que utiliza o estudo de caso como estratégia de levantamento e análise de dados. O caso aborda em profundidade a fase inicial do processo de interação entre uma empresa produtora de eletrodomésticos e panelas e seus fornecedores. O estudo não confirmou integralmente a proposição central, colocada com base na literatura, de que, na fase inicial da interação cliente-fornecedor, a formalização das relações, por meio da introdução de mecanismos de controle e coordenação, abre espaço à emergência da confiança e à troca de informações entre os agentes.
\end{abstract}

Palavras-chave: Relação cliente-fornecedor. Formalização. Controle. Coordenação. Confiança.

\begin{abstract}
The great challenge in the initial phase of the client-supplier interaction is to achieve a level of trust enough to overcome the constraints imposed by the mutual lack of knowledge. Therefore, this study evaluates the behavior of those agents focusing on "learning how to cooperate". The objective is to assess the effects of formal control mechanisms for the building of trusting work environments. This is an explanatory study that uses the case study method to collect and analyze data. The case addresses thoroughly the initial phase of the interaction process between a household appliance and pan manufacturer and its suppliers. The study did not completely corroborate the central proposition, based on relevant literature, that the formalization of relationships, through the introduction of control and coordination mechanisms, in the initial phase of client-supplier interaction promotes trust and exchange of information between the agents.
\end{abstract}

Keywords: Client-supplier relation. Formalization. Control. Coordination. Trust.

\section{Introdução}

No contexto da organização da produção entre as empresas cliente e fornecedora, a fase inicial do relacionamento se caracteriza por níveis elevados de ambiguidade e incerteza, levando a interpretações distintas da relação e, por consequência, a conflitos no acesso às informações e na busca de resolução conjunta de problemas. Se as partes não têm experiência anterior em trabalhar juntas, não conhecem suas capacidades e performances e, sob condições de incerteza, existe o risco da seleção adversa e do dano moral. O primeiro advém da assimetria de informações, situação em que uma das partes interessada em uma potencial transação não possui toda a informação necessária (capacidade técnica do vendedor e qualidade do produto) para determinar se os termos do acordo são aceitáveis e se são viáveis. O "dano moral" emerge quando um dos agentes não tem incentivo para respeitar as suas "promessas", uma vez que o seu comportamento não é observável pelo seu parceiro.

É uma situação de elevada vulnerabilidade financeira e moral (reputação) -, em que a ausência da confiança entre as partes impede o avanço da interação. Assim, na fase inicial da interação cliente-fornecedor, o grande desafio é a obtenção de um grau mínimo de confiança, suficiente para superar a barreira da ausência de conhecimento mútuo e criar um ambiente que estimule a troca de informações e experiências entre os agentes. Emerge daí a questão: como atuar

\footnotetext{
${ }^{1}$ Faculdade Campo Limpo Paulista - FACCAMP, Rua Guatemala, 167, Jardim América, CEP 13231-230, Campo Limpo Paulista, SP, Brasil, e-mail: leonel_mazzalli@uscs.edu.br

${ }^{2}$ Universidade Municipal de São Caetano do Sul - USCS, Av. Goás, 3400, CEP 09550-051, São Caetano do Sul, SP, Brasil
}

Recebido em 27/7/2009 — Aceito em 21/7/2011

Suporte financeiro: Nenhum. 
sobre o comportamento dos agentes e abrir espaço para a criação de um ambiente propício ao "aprender a cooperar"?

A hipótese central, colocada com base no aprofundamento da literatura, é a de que: a formalização das relações, por meio da introdução de mecanismos de controle e coordenação, pode estabelecer foco e transparência ao acordo, abrindo espaço à emergência da confiança e à troca de informações entre os agentes.

O objetivo é identificar e analisar os possíveis nexos entre mecanismos de formalização da relação, confiança e compreensão mútua. É uma pesquisa do tipo explanatório, que utiliza a abordagem do estudo de caso. A unidade de análise é o processo de constituição e desenvolvimento de um grupo de trabalho, composto por diferentes membros de uma empresa produtora de eletrodomésticos e panelas e seus fornecedores, em cujo centro está o desenvolvimento de discos de alumínio com aplicação de antiaderente.

O trabalho está estruturado em oito seções. A primeira é introdutória. A segunda conceitua confiança e aborda a sua importância para o compartilhamento de informações na relação entre empresas. A terceira coloca em discussão o conceito de formalização e avalia as formas de controle e coordenação na relação cliente-fornecedor. Na quarta, é apresentado e discutido o referencial teórico/analítico para o estudo da interação entre formalização (sistema formal de controle) e confiança. A quinta é dedicada aos procedimentos metodológicos. A sexta e a sétima seções, respectivamente, apresentam e discutem o estudo de caso. Finalmente, na oitava seção, algumas conclusões são indicadas e apresentadas possibilidades para futuras pesquisas.

\section{Confiança e compartilhamento de informações na relação entre empresas}

A marca das relações entre cliente e fornecedor é a interdependência e, por consequência, a vulnerabilidade às decisões e ações das partes. A disposição de aceitar a vulnerabilidade (MAYER; DAVIS; SCHOORMAN, 1995) é o núcleo da confiança. Os autores definem confiança como

[...] a disposição de uma parte em se tornar vulnerável às ações de outra, baseada na expectativa de que desempenhará uma particular ação importante independentemente de monitoramento e controle. (MAYER; DAVIS; SCHOORMAN, 1995, p. 712).

Segundo os referidos autores, a confiança tem por referência a benevolência, a integridade e a habilidade. A confiança baseada na benevolência é explicitada por Newell e Swan (2000) como goodwill, ou expectativa de comportamento aberto e honesto, com base nas relações pessoais ou de amizade. A confiança associada à competência envolve a avaliação da capacidade do parceiro executar a sua parte no arranjo, que está atrelada às percepções/ expectativas acerca da habilidade e expertise da outra parte (NOOTEBOOM, 1996). Esse processo não necessariamente ocorre por meio das relações pessoais; o julgamento das competências pode também derivar de aspectos contextuais, tais como reputação da instituição em que a pessoa trabalha ou status profissional do grupo ao qual ela pertence.

Para Dekker (2004), a percepção da competência do parceiro está baseada em aspectos objetivos, conhecimento técnico e habilidade, enquanto o goodwill está baseado em aspectos eminentemente subjetivos, que dizem respeito à ética, à responsabilidade e, de modo particular, sugerem a ausência do comportamento oportunista. Ademais, o goodwill é contextual, assentado em normas de reciprocidade e comportamento que emergem por meio da frequência passada ou esperada das interações. É importante destacar que o goodwill está assentado em percepções das intenções do parceiro, sua integridade e responsabilidade (NOOTEBOOM, 1996).

Expectativas positivas acerca da habilidade, benevolência e integridade da outra parte constituem o insumo da confiança e o resultado é a tolerância ao risco imanente à relação. Quando uma parte decide tornar-se vulnerável ao comportamento das demais, ela assume riscos. Mais precisamente, sem a existência de confiança, o risco atrelado ao relacionamento seria percebido como muito alto, impossibilitando a concretização da interação.

O risco é inerente ao processo de transferência de recursos estratégicos e, em particular, do conhecimento tácito. O relacionamento implica em certos graus de vulnerabilidade para ambos (cliente e fornecedor). De um lado, a parte que é detentora dos recursos (a fonte) torna-se vulnerável porque possibilita acesso a eles. Existe o risco de que a outra parte possa abusar dessa possibilidade, além da probabilidade de que a fonte não seja adequadamente remunerada ou mesmo não obtenha nada em troca. De outro lado, o receptor dos recursos se torna vulnerável por permitir que a fonte reconheça as suas fraquezas.

Uma atmosfera de confiança é fator chave para a conformação de padrões de interação entre os agentes. A confiança ajuda a superação de três importantes barreiras à interação identificadas por Szulanski (1996): distanciamento entre as partes, ambiguidade causal e deficiências na capacidade de absorção de informações e de conhecimento. Como apontado por De Wever, Martens e Vandenhempt (2005), a confiança tem importante papel na motivação dos agentes na 
direção da cooperação, atenuando o denominado "risco relacional" (DAS E TENG, 2001) devido à ameaça do comportamento oportunista.

Vale destacar que a literatura de marketing, voltada ao estudo dos mercados organizacionais ou B2B, reconhecendo a importância crucial da confiança no parceiro de trocas, desenvolveu, ao longo das últimas décadas, esforço acadêmico considerável com o intuito de verificar a sua influência no comportamento das partes e nos resultados da relação. Merecem destaque os estudos empreendidos no Brasil por Brei (2003), Hernandez e Santos (2007), Souza, Ribeiro e Prado (2008). Esses estudos identificaram que a confiança entre as partes conduz à manutenção de relacionamentos mais longos e estáveis, aumenta a satisfação com o relacionamento, o comprometimento e as intenções futuras de compra.

Souza, Ribeiro e Prado (2008) apresentam evidências de que os mecanismos de formalização das relações organizacionais (no caso a presença de fortes acordos contratuais) entre Prestadores de Serviços de Saúde (PSS) e suas principais Operadoras de Plano de Saúde (OPS) estão associados à confiança e à satisfação no relacionamento. Os autores adotaram uma abordagem quantitativa, assentada em uma amostra de 172 relacionamentos, extraída de uma população equivalente a 108.810 PSS.

\section{Sistemas formais de controle na relação cliente-fornecedor}

Em uma relação interorganizacional, a introdução de sistemas formais de controle se apresenta como instrumento fundamental para assegurar que o comportamento e as decisões das partes sejam consistentes com os objetivos e as estratégias do arranjo.

Para Vlaar, Bosch e Volberda (2006), a formalização abrange formas substantivas (contratos, regras e procedimentos) e formas processuais ou estruturantes (codificação, linguagem comum, recompensas e punições). No sistema de organização da produção entre a empresa cliente e a empresa fornecedora, a gestão eficiente dos riscos operacionais, associados à qualidade é ilustrativa. De um lado, a empresa cliente pode instituir formas substantivas, como a definição rigorosa de padrões operacionais (desenho, especificações técnicas de materiais e de processo). De outro, procedimentos estruturantes, atrelados ao estabelecimento de sanções, decorrentes de paradas ou atrasos na linha, e ou apoiados em procedimentos de ajuste/troca de informações.

Dekker (2004), apoiado em Ouchi e Maguire (1975), identifica dois tipos de mecanismos formais de controle nas relações interorganizacionais: obrigações contratuais e sistemas organizacionais (administrativos).

O contrato tem por referência a troca de direitos e a distribuição do poder de decisão entre as partes envolvidas na relação. O objetivo é estabelecer formalmente a "estrutura de governança", tendo por base um conjunto de procedimentos que regem as transações, em particular, no sentido de resolver disputas entre as partes. Embora o contrato possa se constituir em um arcabouço, com clara definição de responsabilidades e prazos, e mesmo um importante indutor das relações de longo prazo na interação cliente-fornecedor, não dá conta da complexidade de ajustes e de realinhamentos que emergem ex-post, isto é, no curso temporal da relação.

Nesse sentido, merece aprofundamento a discussão dos sistemas administrativos de controle, que podem ser classificados tendo em conta o foco "nos resultados" ou "no comportamento dos agentes". O Quadro 1 identifica e classifica os vários sistemas administrativos de controle, destacando também a sua funcionalidade.

O controle sobre os resultados envolve a definição de metas, a mensuração e a avaliação do desempenho das operações, destacando-se, no âmbito das relações cliente-fornecedor, padrões de qualidade e de prazos de entrega. A fixação de objetivos estabelece direções para a perfomance das atividades, deixa transparentes as expectativas e aumenta a congruência de objetivos, em particular quando as recompensas estão explicitamente atreladas ao seu alcance.

Por meio da supervisão e da criação de canais de comunicação, o controle sobre o comportamento dos agentes visa aumentar a interação e o comprometimento dos agentes. No âmbito dos mecanismos ex-ante de controle do comportamento, Mintzberg (1979) destaca a importância de seis considerados básicos: ajustamento mútuo, supervisão direta, padronização de processos, padronização de saídas, padronização de habilidades e padronização de normas. Em síntese: planejamento, programas, regras, procedimentos operacionais e procedimentos específicos de resolução de conflitos.

A análise da performance do comportamento dos agentes utiliza-se de elementos como relatórios de acompanhamento das atividades, controle de custos e controle de qualidade.

Vélez, Sánchez e Álvarez-Dardet (2008) e Dekker (2004) chamam a atenção para o fato de que os sistemas administrativos de controle podem assumir diferentes funções (usos) na gestão da relação interorganizacional, dependendo da intenção que orienta o seu desenho.

Dekker (2004) identifica duas funções do sistema formal de controle: monitoramento e coordenação.

A função monitoramento está direcionada à avaliação do desempenho e à recompensa pelo 
Quadro 1. Sistemas de controle administrativo na relação interorganizacional.

\begin{tabular}{|c|c|c|}
\hline \multicolumn{2}{|r|}{ Tipos } & \multirow[t]{2}{*}{ Usos (Funcionalidade) } \\
\hline Foco & Mecanismos & \\
\hline \multirow[t]{7}{*}{ Resultado } & Ex-ante & Monitoramento (DEKKER, 2004) \\
\hline & Fixação de metas/objetivos & O objetivo central do controle é medir e recompensar a \\
\hline & Sistema de incentivos & performance por meio da supervisão do grau de \\
\hline & Estrutura de recompensas & alcance das metas. \\
\hline & Ex-post & A intenção é reduzir o comportamento oportunista \\
\hline & Monitoramento da performance & e as divergências entre as partes, provendo claros sinais \\
\hline & e recompensas & para o alinhamento de interesses. \\
\hline \multirow[t]{13}{*}{ Comportamento } & Ex-ante & Coordenação \\
\hline & Especificações estruturais & 1. Operacional (DEKKER, 2004) \\
\hline & a) planejamento & A necessidade do controle advém da divisão de tarefas, \\
\hline & b) procedimentos & entre os parceiros, de diferentes especializações e \\
\hline & c) regras e regulamentos & de diferentes tipos de conhecimento e capacidades. \\
\hline & Ex-post & A preocupação central é a interdependência de \\
\hline & Monitoramento do & atividades. \\
\hline & comportamento e recompensas & O sistema de controle gera, atualiza e compartilha a \\
\hline & & $\begin{array}{l}\text { informação necessária para reduzir a incerteza e } \\
\text { promover a ntegração entre as partes. }\end{array}$ \\
\hline & & A ênfase recai na tomada de decisões e na resolução \\
\hline & & de problemas. \\
\hline & & $\begin{array}{l}\text { 2. Relacional (VOSSEOLMAN; } \\
\text { MEER-KOOISTRA, 2004, 2009) }\end{array}$ \\
\hline & & $\begin{array}{l}\text { Emissão de sinais de cooperação entre os agentes, } \\
\text { visando a construção de um quadro de referência } \\
\text { comum. }\end{array}$ \\
\hline
\end{tabular}

Fonte: adaptado de Dekker (2004).

alcance de padrões desejados. O objetivo é reduzir a possibilidade do comportamento oportunista, por meio da emissão de sinais explícitos de reforço ao alinhamento dos interesses individuais ao acordo interorganizacional.

A função coordenação deriva da especialização e da divisão de trabalho entre os agentes. A interdependência entre tarefas exige o alinhamento de decisões e ações, levando ao planejamento e à resolução conjunta de problemas. A preocupação central é a interdependência de atividades, demandando a criação de mecanismos organizacionais de integração. As interações do dia a dia são construto central desse tipo de coordenação, delineando a forma pela qual as partes coordenam os processos, o que requer o desenvolvimento de fluxos de comunicação, de mecanismos para o compartilhamento de informações e do ajuste nas atividades de cada um.

No âmbito da função coordenação, Vosselman e Meer-Kooistra $(2004$, 2009) procedem a uma distinção entre o campo operacional e o campo relacional. No campo operacional, o sistema formal de controle atua como suporte à coordenação das atividades no interior da relação, visando eficiência e eficácia. No campo relacional, o sistema formal de controle se apresenta como a base de um processo de emissão de sinais de cooperação entre os agentes, visando à construção de um quadro de referência comum (frame) que, ao estreitar laços, sustenta o relacionamento.

Sob a perspectiva do campo relacional, o sistema formal de controle se insere em um processo de aprendizagem relacional e de construção da confiança. Nesse sentido, a noção de controle vai muito além da tradicional. Não se trata de avaliar, incentivar e ou restringir o comportamento dos parceiros, por meio da presença de um centro hierárquico preocupado com a atuação das partes. O foco é a obtenção do comprometimento entre as partes, por meio da emissão voluntária de sinais (direcionadores cognitivos) que reforçam o comportamento cooperativo.

Nesse sentido, abre-se a discussão sobre a interação dinâmica entre sistema formal de controle e confiança (objetivo central do trabalho). 


\section{A interação dinâmica entre formalização (sistema formal de controle) e confiança}

Knights et al. (2001) assinalam a existência de uma longa tradição que apresenta o sistema formal de controle e a confiança como alternativos. A perspectiva substitutiva sugere que confiança e controle estão inversamente relacionados. Quanto maior o grau de confiança, menor o controle, e vice-versa. A introdução do contrato e de outros tipos de sistemas formais de controle decorre da ausência de confiança entre as partes. Ademais, esse expediente, ao ser interpretado como "desconfiança" no comportamento dos parceiros, reduz ou elimina a possibilidade de criar um ambiente favorável à confiança.

Coletti, Sedatole e Towry (2005) criticam a perspectiva substitutiva pelo fato de considerar o grau de cooperação entre as partes constante, inserindo a relação entre confiança e controle em um "cálculo de soma zero", isto é, cada incremento no sistema formal de controle, ou na confiança, pressupõe o decréscimo correspondente no outro. A sua proposição é a de que os sistemas formais de controle podem aumentar diretamente a cooperação e indiretamente aumentar a confiança.

Langfield-Smith e Smith (2003) e Poppo e Zenger (2002), defensores da abordagem da complementaridade, reafirmam o argumento de que o sistema formal de controle promove a expectativa de cooperação, gerando comprometimento ao relacionamento e, por conseguinte, maior confiança. Controle e confiança mutuamente se reforçam.

Para Tomkins (2001), as duas abordagens, substitutiva e complementar, ignoram o processo dinâmico de construção da confiança. $\mathrm{O}$ autor identifica quatro estágios no ciclo de vida do relacionamento entre empresas: pré-relacionamento, exploratório, desenvolvimento e estabilidade. Sua proposição é que a influência do sistema formal de controle sobre a confiança não é uniforme, podendo ser caracterizada, ao longo do ciclo de vida da relação, como uma curva em forma de $\mathrm{U}$ invertido.

Explorando a interação entre a informação contábil (decorrente de um sistema formal de controle) e a confiança, o autor sugere que, nos estágios iniciais do relacionamento entre empresas, o controle pode gerar confiança. A troca de informação contábil (sistemas de custos e outros procedimentos de controle financeiro) pode produzir expectativas positivas sobre as condições futuras do relacionamento, atuando como estímulo ao comprometimento dos agentes. Nos estágios mais avançados do relacionamento, a confiança entre os parceiros atinge um máximo e permanece constante, de modo que incrementos no sistema de controle podem ser prejudiciais ao grau de confiança pré-existente.
Dekker (2004) explora os efeitos das diferentes funções e significados do sistema formal de controle - monitoramento e coordenação - sobre o grau de confiança. Para o autor, o monitoramento pode produzir efeitos negativos sobre a confiança, porque implicitamente assume a prevenção contra o comportamento oportunista, isto é, a desconfiança lhe é subjacente. No entanto, a função coordenação, por estar associada à complexidade/interdependência das tarefas e à importância estratégica da relação, não carrega a conotação negativa atrelada à função monitoramento. Enquanto instrumento de coordenação, o sistema formal de controle é utilizado para compartilhar informações constituindo-se em um importante determinante da confiança.

Dekker (2004) enfatiza a função coordenação. As partes utilizam o sistema formal de controle para coordenar a execução de tarefas complexas e, nesse processo, a confiança pode ser gerada, na medida em que aumentar a transparência e a percepção de justiça nos acordos. Nesse aspecto é fundamental a contribuição de Vosselman e Meer-Kooistra (2004, 2009). Como assinalado anteriormente, os autores procedem a uma distinção entre o campo operacional e o campo relacional da coordenação, acentuando a importância deste último para o desenvolvimento da confiança no interior do relacionamento.

A questão central é investigar quais procedimentos decisórios os agentes adotam, no curso da relação, para se prevenir contra o comportamento oportunista. Esses procedimentos estão associados à percepção e à compreensão que as partes têm da relação. $\mathrm{O}$ objetivo é deixar transparente, ao conjunto dos agentes, o enfraquecimento da busca exclusiva de objetivos individuais, o que requer a definição precisa dos objetivos do acordo e a emissão de sinais que os reforçam, criando um quadro de referência (frame) para a atuação dos agentes.

Vosselman e Meer-Kooistra (2004) consideram ainda a interação positiva entre a função monitoramento e a função coordenação (no campo da emissão de sinais de relacionamento). Em contraponto a Das e Teng (2001), os autores propõem que o estabelecimento de controles rígidos das ações e dos resultados pode proporcionar objetividade à relação e transparência mútua, gerando um ambiente de confiança entre as partes.

Em síntese, o contrato e outras formas de controle formal podem ter vários efeitos para a relação entre os agentes, dependendo da forma e das intenções que governaram a sua redação e a sua implementação. De um lado, a utilização instrumental e burocrática do controle pode estar estritamente associada ao monitoramento rígido das operações, produzindo um ambiente de baixa confiança ou de questionamento da confiança, impedindo que os agentes demonstrem suas capacidades (competências) e intenções. De 
modo alternativo, pode ajudar a edificar um "objetivo comum", criando um contexto de compartilhamento de tarefas, de informações e de benefícios.

Inserido no campo teórico liderado por Tomkins (2001), Dekker (2004) e Vosselman e Meer-Kooistra (2004, 2009), o foco deste trabalho recai na fase inicial do relacionamento entre organizações que não se conhecem suficientemente, configurando uma situação marcada pelo elevado grau de incerteza associado ao comportamento das partes.

A contribuição teórica deriva da identificação de potenciais mecanismos de geração de confiança na fase inicial do relacionamento entre empresas. Mais especificamente, pretende-se esclarecer como a introdução de sistemas formais de controle/ coordenação pode se constituir em mecanismo indutor de um nível mínimo de confiança entre as partes, suficiente para garantir o início do relacionamento.

A proposta é demonstrar que, além de propiciar monitoramento e coordenação, o escopo do sistema administrativo de controle na fase inicial da relação cliente-fornecedor pode contemplar:

- A criação de um ambiente comum que favorece a transparência de interesses, podendo redundar na criação do goodwill e, por consequência, no estímulo ao compartilhamento de informações; e

- A oportunidade dos agentes demonstrarem suas competências, dentro de limites estabelecidos, trazendo à cena o caráter objetivo da transação e, dessa forma, a efetiva contribuição, em termo de recursos que os agentes podem aportar ao arranjo, dando origem à confiança assentada na habilidade.

A Figura 1 sintetiza as relações levadas para investigação empírica.

\section{Procedimentos metodológicos}

Em essência a investigação empírica objetiva compreender "como" a relação cliente-fornecedor evolui ao longo do tempo, na sua fase inicial, inserindo-se em uma abordagem que tem como foco o processo de mudança no comportamento dos agentes, associado à introdução de mecanismos voltados à formalização da relação. De acordo com Langley (1999), a marca dessa abordagem é o delineamento longitudinal, isto é, a análise temporal do processo de mudança e da influência das ações e percepções dos agentes sobre os resultados da mudança. $\mathrm{O}$ objeto da investigação é

[...] a sequência de eventos e (inter) ações no interior e entre partes organizacionais que conformam e modificam o relacionamento (contratual) ao longo do tempo. (NESS, 2001, p. 20).
No âmbito do delineamento temporal, o método do estudo de caso se apresenta como estratégia apropriada de pesquisa. O estudo de caso objetiva explicações holísticas do fenômeno e, face à flexibilidade no delineamento e na coleta de dados, permite o aprofundamento da análise, desempenhando, como apontado por Eisenhardt (1989) e Gummesson (2000), importante função na construção de teorias.

Smith, Carroll e Ashford (1995) foram os primeiros a enfatizar a necessidade de estudos de caso longitudinais para analisar a complexidade e a dinâmica da cooperação entre empresas. Bhimani (2003), Cooper e Slagmulder (2004), Dekker (2004), Kamminga e Meer-Kooistra (2007), Langfield-Smith e Smith (2003) e Meer-Kooistra e Vosselman (2000) utilizaram o método do estudo de caso (caso único e multicaso) na investigação da interação entre o sistema de controle/coordenação e o grau de confiança no interior do relacionamento interorganizacional, destacando como vantagem a superação do caráter estático dos estudos quantitativos com corte temporal.

Na presente pesquisa, optou-se pelo estudo de caso único, por se tratar, de acordo com Yin (2010, p. 72) de "[...] caso longitudinal: o estudo de um mesmo caso único em dois ou mais pontos diferentes do tempo."

$\mathrm{O}$ caso analisa em profundidade a fase inicial do processo de interação entre uma empresa produtora de eletrodomésticos e panelas e seus fornecedores, em cujo centro está o desenvolvimento de discos de alumínio com aplicação de antiaderente. A unidade de análise é o processo de constituição e desenvolvimento de um grupo de trabalho, composto por diferentes membros da organização cliente e das organizações fornecedoras, apresentadas com nomes fictícios. São dois os objetivos da análise. Em primeiro lugar, identificar os mecanismos formais de controle utilizados para sustentar a constituição e a administração das interações entre os agentes integrantes do grupo de trabalho interorganizacional. Em segundo lugar, avaliar o efeito dos mecanismos formais de controle na geração de um ambiente favorável à emergência da confiança.

Os principais métodos de coleta de dados foram: análise de documentação e entrevistas com representantes das diferentes organizações que fizeram parte do "grupo de trabalho". Como um dos autores participou ativamente em todas as fases do processo, foi possível também obter informações valiosas decorrentes do acompanhamento e da observação direta dos fatos - "observação participante" (WHYTE, 1991).

Os documentos possibilitaram a identificação com precisão das datas dos eventos e, mais importante, permitiram estabelecer a cronologia dos eventos. Os principais documentos utilizados foram: manuais e procedimentos para efetivação de testes do produto/ 


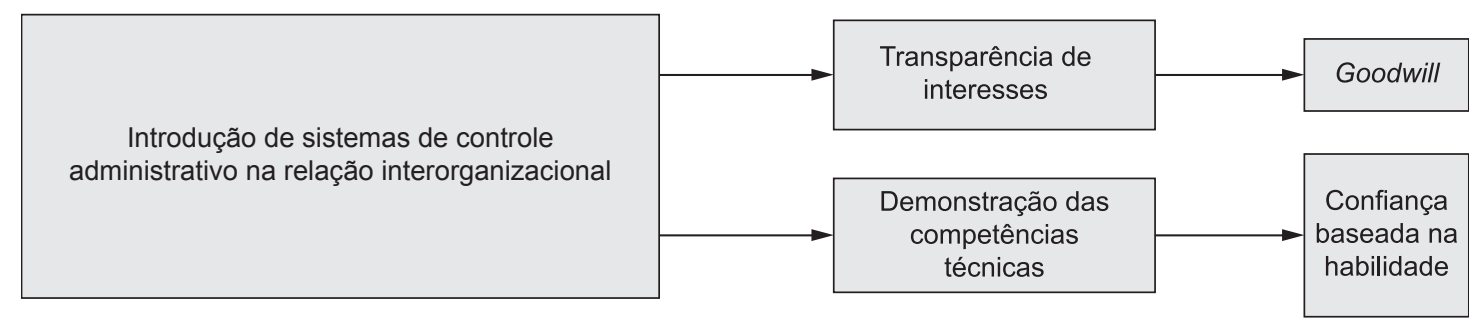

Figura 1. Os prováveis efeitos da introdução de sistemas administrativos de controle na fase inicial da relação clientefornecedor sobre a confiança entre os agentes.

materiais, e, particularmente, agendas, atas e minutas das reuniões regulares realizadas entre os agentes.

As entrevistas, conduzidas à medida que o processo de relacionamento do grupo de trabalho se desenrolava, foram realizadas com os representantes da empresa cliente e das empresas fornecedoras. No caso da empresa cliente, foi o gerente do departamento de controle da qualidade. Na empresa fornecedora de panelas e na empresa fornecedora de discos de alumínio, foram os gerentes industriais. Na empresa fornecedora de antiaderente, o entrevistado foi o gerente de desenvolvimento.

As entrevistas foram utilizadas para obter informações relativas a objetivos, interesses, táticas, ações e resultados. Juntamente com a observação direta, permitiram trazer à tona a realidade das ações e reações dos agentes.

$\mathrm{Na}$ identificação dos mecanismos de controle formal, foi adotado o enfoque sintetizado no Quadro 1.

Da perspectiva do goodwill, o grau de confiança entre os agentes foi identificado a partir da análise do processo de comunicação entre os agentes, com especial atenção para a existência (ou não) de conflitos (BSTIELER, 2006). Para o autor, existe uma estreita relação entre o goodwill, o fluxo e a qualidade da comunicação entre os agentes.

Da perspectiva da expertise (habilidade), o grau de confiança entre os agentes foi identificado com base na análise do processo de resolução de problemas operacionais entre os agentes. Para Bstieler (2006), existe uma relação entre a expertise e o processo de tomada de decisão conjunta na resolução de problemas. No processo de resolução conjunta de problemas, foram consideradas a oportunidade de experimentar/ errar e a busca de feedback/instruções junto aos demais agentes. Por sua vez, o conflito emerge a partir das percepções dos agentes quanto aos objetivos e papéis (responsabilidades) no relacionamento, as quais se refletem no comprometimento e na satisfação com a interação.

Para Gummesson (2000), a validade interna do método do estudo de caso deve ser apreendida com base no confronto (dialética) entre teoria e realidade. Assim, a proposição central, obtida a partir da revisão da literatura, que orientou a interpretação dos dados foi a seguinte: na fase inicial da interação clientefornecedor, a formalização das relações, por meio da introdução de mecanismos de controle e coordenação, não causa inflexibilidade no relacionamento entre as partes, ao contrário, estabelece foco e transparência ao acordo, abrindo espaço à emergência da confiança e à troca de informações entre os agentes. O fio condutor é, portanto, a introdução de sistemas de coordenação/ controle e a análise, ao longo do tempo, do seu efeito sobre a confiança entre os agentes.

Para estruturar e interpretar os dados longitudinais em relação à proposição teórica, a técnica analítica utilizada, a partir das considerações de Yin (2010) sobre a análise das evidências do estudo de caso, foi a "análise de séries temporais". Mais precisamente, foi adotada uma forma especial da análise de séries temporais, denominada por Yin (2010, p. 175) de "análise de eventos cronológicos", que permite o rastreamento dos eventos ao longo do tempo.

No âmbito da análise temporal dos processos, Langley (1999) e Rowe, Birnberg e Shields (2008) dão destaque à técnica analítica denominada "escalonamento temporal", que se baseia, como enfatizado por Yin (2010, p. 177), na identificação de um indicador específico (no caso eventos) a ser rastreado ao longo do tempo, assim como dos intervalos de tempo específicos a serem cobertos e dos relacionamentos temporais presumidos entre os eventos.

A técnica divide a extensão de tempo do caso em estudo em subperíodos (ou fases), a partir de eventos que marcam rupturas ou descontinuidades (dentre essas rupturas, destaca-se a introdução de mecanismos de controle/coordenação da relação cliente-fornecedor). No caso em estudo foram identificadas três fases: fase 1 - exploratória (seleção de fornecedores e gestão da qualidade); fase 2 - formação de um grupo de trabalho multiempresas para a gestão conjunta da qualidade - e fase 3 - grupo em ação.

Como acentua Langley (1999), cada período de tempo (fase) é utilizado como base para comparações. Além de identificar a evolução do comportamento dos agentes no interior de uma determinada fase, é possível captar mudanças na trajetória do comportamento dos agentes entre fases, face à ocorrência de determinados 
eventos, no caso a introdução de procedimentos formais de controle.

\section{A constituição e o desenvolvimento da relação fornecedor-cliente na cadeia de produção de utensílios domésticos}

\subsection{Antecedentes e origem do relacionamento}

A Eletrodomésticos AR foi adquirida em 1997 por um grupo francês líder mundial na fabricação de eletro portáteis. Além de expandir sua atuação no segmento original, a empresa incorporou uma nova unidade de negócio: panelas com antiaderente.

O início da operação da nova unidade de negócio ocorreu em pequena escala, com a instalação de parque fabril destinado a realizar apenas a montagem e a embalagem do produto. O disco de alumínio com aplicação de revestimento antiaderente, principal insumo, era importado da matriz europeia, representando $60 \%$ do custo total do produto. As variações cambiais ocorridas em 2002 e em 2003 conduziram à decisão de recorrer a fornecedores nacionais. Não se julgou adequado estabelecer uma unidade própria para produção local do insumo, pois exigia elevado investimento e significativo aumento de participação no mercado.

Face à especificidade do insumo, a Eletrodomésticos AR deveria convencer as empresas processadoras do mesmo produto, concorrentes, a se transformarem em fornecedoras. A empresa Panelas NA foi escolhida, sendo que duas das matérias-primas utilizadas para a obtenção do insumo seriam fornecidas pelas empresas Alumínio CA (disco de alumínio) e Revestimento WW (antiaderente a ser aplicado sobre o alumínio).

A Panelas NA é uma empresa brasileira com rede de distribuição em todo o território nacional e em países da Europa e da Ásia. A Revestimento WW conta com instalações industriais em sete países, atuando no revestimento de panelas, fôrmas/frigideiras e em aplicações industriais e resistência à corrosão. A Alumínio CA é uma empresa brasileira especializada na fabricação de discos acabados, bobinas, chapas, laminados, trefilados e rebites de alumínio.

\subsection{Fase exploratória da relação: seleção dos fornecedores e gestão da qualidade}

A estratégia inicial do projeto, estabelecida pela Eletrodomésticos AR, foi delegar ao departamento de Suprimentos o desenvolvimento de possível fornecedor, definindo o diretor da área como responsável pela prospecção, desenvolvimento e assinatura de contrato de abastecimento. Esta fase, que teve uma duração de seis meses, foi acompanhada por um grupo interno da Eletrodomésticos AR, composta por gerentes dos departamentos de Suprimentos, Marketing e Engenharia de Produtos. A dinâmica deste grupo era a de realizar visitas aos potenciais fornecedores, recolher amostras e encaminhá-las para a matriz na Europa, que realizava os testes técnicos.

Nessa fase, quatro possíveis fornecedores foram prospectados e sondados, três dos quais declinaram do negócio. A escolha do fornecedor - Panelas NA - teve como base o custo e a "aceitabilidade" de fornecimento. Após essa definição, a Eletrodomésticos AR estabeleceu os fornecedores dos discos de alumínio e do antiaderente, respectivamente, Alumínio CA e Revestimento WW. À Panelas NA caberia preparar a superfície do disco de alumínio, para, em seguida, realizar a aplicação do antiaderente e, finalmente, passar por um forno para realizar a "cura" final do produto. Uma vez concluído este processo, o disco de alumínio seria enviado à Eletrodomésticos AR, que realizaria a estampagem, a montagem do cabo e a embalagem do produto final.

Vale destacar que o projeto estava diretamente atrelado à redução de custo do item importado, de modo que o preço foi o principal fator que influenciou a seleção das três empresas fornecedoras em cadeia. As ligações entre os agentes foram pautadas por aspectos financeiros, com reduzida interação técnica. Esta situação deixou a unidade local da Eletrodomésticos AR sem uma base de conhecimento técnico mais profunda do processo de fabricação.

A matriz do grupo europeu possuiu, no passado, algum tipo de ligação com dois dos fornecedores selecionados. A Panelas NA realizou atividades comerciais com a matriz do grupo europeu antes deste adquirir a Eletrodomésticos AR. Por sua vez, o presidente da Revestimento WW trabalhou como diretor da Eletrodomésticos AR por vários anos.

Quando da entrada do primeiro lote na linha de produção da Eletrodomésticos AR, os ensaios de recebimento constataram a sua inadequação. A decisão de recusar o lote estava embasada na acentuada degradação do produto nos estágios iniciais de uso. Essa decisão tornou-se mais fundamentada mediante a realização de ensaios comparativos entre amostras da matriz e as da concorrência.

Nos dois tipos de ensaios (laboratorial e prático) ficou comprovado que a empresa Panelas NA não possuía a metodologia e as especificações necessárias à realização dos referidos ensaios. Por esta razão e atendendo à realização dos ensaios de recebimento e de durabilidade, foi criado um grupo de trabalho composto pelos funcionários da área de qualidade das duas empresas, que ficou responsável pelo planejamento e pela execução dos testes. O resultado do trabalho do grupo foi o estabelecimento de uma 
rotina básica de testes, fundamentada nos resultados esperados pelo produto em condições normais de uso.

Como a empresa cliente não dispunha de conhecimento prévio para subsidiar as suas ações, pois todo o desenvolvimento do produto fora realizado na matriz, criou-se um problema, agravado pelo conflito entre as áreas responsáveis pelo desenvolvimento e pelo ensaio que reprovara o lote. Cabe destacar que havia, por parte da matriz, o receio de que o compartilhamento da tecnologia com a unidade brasileira pudesse ser involuntariamente repassado à Panelas NA, o que fundamentava a negativa de envio dos testes e dos resultados obtidos pela matriz na etapa de aprovação das amostras.

Esta ação baseava-se no entendimento de que pequenas variáveis teriam causado a reprovação do lote, e que pequenos ajustes possibilitariam o estabelecimento da qualidade necessária. No entanto, o departamento da qualidade da Eletrodomésticos AR identificou um grande potencial de deficiências, pois a Panelas NA estava utilizando insumos, alumínio e antiaderente, diferentes de seu padrão de produção, fato este que indicou a necessidade de inclusão no projeto dos fornecedores dos respectivos insumos.

O Quadro 2 apresenta de forma sintética as fases da evolução da relação envolvendo a Eletrodomésticos AR e os três fornecedores (Panelas NA, Alumínio CA e Revestimento WW), com destaque para os eventos caracterizadores e para as variações na confiança entre os agentes.

\subsection{Formação de um grupo de trabalho multiempresas para a gestão conjunta da qualidade}

Em função dos problemas ocorridos, a direção da Eletrodomésticos AR alterou a responsabilidade pela gestão do projeto, da área de Suprimentos para a área industrial, pois as reprovações estavam sendo realizadas nessa esfera e percebeu-se a necessidade de aquisição de novos conhecimentos para a continuidade do projeto. Nessa nova abordagem, foi constituído um novo grupo de pesquisa composto, de um lado, pelos gerentes da Eletrodomésticos $\mathrm{AR}$, nas áreas de suprimentos, marketing, engenharia de produto e controle da qualidade, e, de outro, por representantes das empresas fornecedoras.

Nesse grupo, a Panelas NA era representada pelo gerente industrial, a Alumínios CA pelo gerente industrial e a Revestimentos WW pelo gerente de desenvolvimento. As empresas fornecedoras estabeleceram grupos internos de apoio, mas a identidade dos membros não foi revelada à empresa cliente, de modo que toda a informação estava centralizada no representante. Essa condição não era interpretada como a melhor pela Eletrodomésticos AR, mas atendia às necessidades para a continuidade do projeto.

Em reunião realizada na Eletrodomésticos AR com os membros do grupo de trabalho e as respectivas diretorias, foram definidos os seguintes padrões de conduta, identificados em ata do encontro:

- todos os membros do grupo se reuniriam quinzenalmente na sede da Panelas NA para análise dos resultados observados no período;

- as ações seriam acordadas por todos os membros do grupo e descritas em relatório sob responsabilidade da Eletrodomésticos AR;

- os resultados observados seriam apontados em relatório para a divulgação na reunião quinzenal; e

- a Panelas NA receberia e daria suporte aos demais membros do grupo no acompanhamento da realização dos testes e lotes de produção.

Estabeleceu-se ainda um prazo máximo de quatro meses para a conclusão do projeto. O prazo era maior do que o pretendido pela Eletrodomésticos AR, mas foi apontado como o possível para atender às necessidades de desenvolvimento. O objetivo inicial do grupo era identificar e analisar as variáveis que interferiam na qualidade do insumo e posteriormente atuar no sentido de propor melhorias nos componentes e no processo de manufatura. Como o entendimento das variáveis que interferiam no processo era de domínio exclusivo de cada uma das empresas fornecedoras, a constituição do grupo tinha por objetivo o compartilhamento do conhecimento por elas detido.

\subsection{O grupo em ação (transparência de interesses e de habilidades/ competências dos agentes)}

Houve dificuldades de acesso às instalações industriais e à tecnologia envolvida no processo das empresas fornecedoras de discos e revestimentos, configurando-se, inicialmente, uma abordagem parcialmente colaborativa, incluindo-se a Panelas NA. Apesar de não ocorrer uma negativa formal, era notória a argumentação, explicitada nas entrevistas realizadas, de dificuldades associadas à programação dos lotes e às restrições de agenda para realizar os testes.

Embora muitas dificuldades tenham sido superadas, mediante a decisão da Eletrodomésticos AR de assumir os custos referentes à rejeição do primeiro lote fornecido, as informações relevantes do processo continuaram a ser omitidas pelas partes.

Apesar da baixa colaboração, conforme acordado anteriormente entre as partes, se iniciou a fase de planejamento, realizando-se a primeira reunião de trabalho do grupo, na qual se contemplou a necessidade de estabelecer ensaios padronizados voltados à confirmação da qualidade final do produto 
Quadro 2. Fases da Evolução do Relacionamento da Eletrodomésticos AR com os fornecedores.

\begin{tabular}{|c|c|}
\hline Fase/principais eventos & Variações na confiança \\
\hline \multicolumn{2}{|c|}{ 1. Exploração da relação cliente-fornecedor e gestão da qualidade } \\
\hline $\begin{array}{l}\text { 1.1. Escolha dos fornecedores: Panelas NA, } \\
\text { Aluminio CA (disco de aluminio) e Revestimento } \\
\text { WW (antiaderente). } \\
\text { 1.2. Constatação da inadequação do produto } \\
\text { 1.3. Decisão de constituir um grupo de trabalho } \\
\text { composto pelos gerentes da Eletrodomésticos AR } \\
\text { e por representantes das empresas fornecedoras, } \\
\text { com o objetivo de adquirir e aprofundar o } \\
\text { conhecimento do processo }\end{array}$ & $\begin{array}{l}\text { Ligações pautadas por aspectos financeiros, } \\
\text { com reduzida interação técnica } \\
\text { Ausência de conhecimento técnico do processo como um todo: } \\
\text { a) a empresa cliente não dispunha de conhecimento prévio } \\
\text { para subsidiar suas ações; } \\
\text { b) a empresa Panelas NA não possuia a } \\
\text { metodologia e as especificações necessárias } \\
\text { para a realização dos ensaios técnnicos. }\end{array}$ \\
\hline
\end{tabular}

\section{Fomação de grupo de trabalho multiempresas/gestão conjunta da qualidade}

2.1. Definição de padrões de conduta do grupo: agenda das reuniões e especificação de relatórios descritivos das ações e dos resultados

2.2. Definição da infra-estrutura de suporte

2.3. Definição de prazos para as etapas e

conclusão do projeto
O fato dessa definição ter sido realizada em reunião com a presença das diretorias é revelador do caráter formal que cercou as decisões tomadas

\section{Grupo em ação}

3.1 Dificuldades de acesso às instalações industriais e à tecnologia de processo das empresas fornecedoras de discos e revestimentos Omissão de informações relevantes do processo produtivo.

3.2 Primeira reunião do grupo de trabalho:

a) establecimento de procedimentos para padronização dos ensaios;

b) instituição de controles intermediários para verificação da adequação do processo de fabricação na Panelas NA.

\subsection{Documentação e compartilhamento do} conhecimento gerado no primeiro ciclo de planejamento, fabricação e ensaios de amostras 3.4. Sequência de novos ciclos de planejamento, de ações e de verificação da adequação dos resultados obtidos
No âmbito do goodwill, abordagem parcialmente colaborativa No âmbito das habilidades, receio de transferência de conhecimento e knowhow associado à aplicação de antiaderente em superfícies de alumínio
Emergência do goodwill, incentivado pela observação de interesse de todos os membros do grupo e pelos resultados promissores que se apresentavam. Os agentes passaram a manifestar "boa vontade" em compartilhar informações, além de explicitar com maior clareza os interesses específicos.

A aquisição do conhecimento do processo como um todo redundou na transparência das competências técnicas dos agentes, mas o resultado não foi a emergência da confiança no expertise dos parceiros:

a) para a Eletrodomésticos AR e para a Panelas NA foi fundamental, abrindo a perspectiva de novos fornecedores;

b) para a Aluminios CA e para a Revestimento WW, revelou a incompatibilidade do processo e a inadequação dos produtos oferecidos.

Fonte: elaborado pelos autores. 
e aos controles intermediários a serem utilizados para verificação da adequação do processo de fabricação na Panelas NA. Os ciclos seguiam a proposta PDCA de Deming, com o planejamento inicial das atividades envolvendo recursos e responsabilidades. A fase de realização era assistida por representantes das empresas envolvidas e a fase de verificação consistia no controle dos produtos manufaturados e nos testes de adequação ao uso. Quando os resultados obtidos fossem satisfatórios, seriam incorporados à linha de produtos.

O primeiro ciclo de planejamento, fabricação e ensaios de amostras detectou a causa da reprovação inicial: a Panelas NA voluntariamente não aplicou um elemento químico que provocava uma diferença de brilho nos produtos, implicando no 'desplacamento' do revestimento durante a sua utilização. Com essa constatação, foi ultimado um novo lote amostral, objetivando a confirmação de que a inclusão do elemento químico resultava em um produto de melhor qualidade. Esse lote foi submetido à sequência de ensaios proposta pela Eletrodomésticos AR, tendo sido novamente reprovado.

O conhecimento derivado do primeiro ciclo de desenvolvimento foi documentado e compartilhado pelas empresas - cliente e fornecedoras -, com destaque para a influência positiva do elemento químico responsável pelo brilho na qualidade do produto, mas com a constatação de que outras variáveis estavam atuando no processo.

Face ao resultado negativo, ocorreu o desencadeamento de uma sequência de novos ciclos de planejamento, de ações e de verificação da adequação dos resultados obtidos - PDCA. Essa sequência foi necessária, pois, a cada novo lote realizado para confirmar a solução de um problema, descobria-se uma nova variável interferindo no processo, sendo esse conhecimento compartilhado por todos os membros do grupo.

As entrevistas realizadas com os membros do grupo de trabalho revelaram um clima de "descontração" na relação, em que os agentes sentiam disposição de revelar interesses e expectativas. Nesse momento, parece ter emergido o goodwill, no qual os agentes, embora ainda não possuindo uma visão completa e integrada do processo produtivo, manifestam "boa vontade" em compartilhar informações, além de explicitar com maior clareza os interesses específicos. Como as partes passaram a trabalhar com o mesmo sistema de informação e criaram um fórum de debates para discussão dos problemas associados à gestão da qualidade, aumentou o grau de integração e de percepção das intenções.

Os representantes da Eletrodomésticos AR dedicavam atenção especial à análise das informações obtidas nos testes com o objetivo de construir conhecimento do produto e do processo. A Panelas NA aproveitou a oportunidade para se aproximar de novos fornecedores - alumínio e antiaderente -, sem arcar com os custos envolvidos. Ademais, como seu quadro técnico estava baseado exclusivamente na figura de um consultor externo, a participação no projeto permitiu auferir conhecimento sobre o seu processo de fabricação. A Alumínio CA identificou no projeto a possibilidade de ocupar a capacidade ociosa de suas instalações, mas é possível supor o seu entendimento das restrições que se apresentariam à sua matéria-prima, pois a sua competitividade estava baseada em custos relacionados a um material composto de uma parcela significativa de reciclagem, impactando na qualidade dos processos de aplicação de antiaderente e de estampagem. A Revestimentos WW vislumbrou grandes benefícios em participar do projeto, pois o abastecimento do antiaderente para a Eletrodomésticos AR associaria seu nome à empresa matriz, que possui renome na fabricação de panelas, possibilitando se apresentar ao mercado como uma empresa fornecedora de antiaderentes de alta qualidade.

Após a realização do terceiro ciclo PDCA (terceiro experimento), a Eletrodomésticos AR adquiriu um conhecimento considerável que possibilitou a realização de experimentações internas, embora em pequena escala.

A realização dos testes era acordada nas reuniões do grupo multiempresas e a média era de duas a três experimentações por semana, que ocorriam na Panelas NA. As experimentações não demandavam a necessidade da presença de todos os envolvidos, com exceção da Eletrodomésticos AR, que estabeleceu a estratégia de contar com um funcionário na realização de todos os ensaios. Os resultados eram compartilhados com os demais membros do grupo, objetivando o processo de construção de confiança entre as partes.

As várias sequências de testes realizados pelo grupo de trabalho multiempresas possibilitaram a aquisição de novos conhecimentos, com destaque para:

- Uma variável relacionada à hidratação de um dos componentes químicos, que não era monitorada, de extrema importância para o resultado final;

- A necessidade de um bom acabamento na superfície do material antes da aplicação do revestimento;

- As concentrações dos elementos químicos utilizados nos banhos de preparação da superfície interferiam na qualidade final, fazendo-se necessário alterar a composição; e

- O revestimento/antiaderente aplicado sobre o alumínio é fundamental para o desempenho da panela, evitando que os alimentos possam aderir ao produto. 
Em relação ao revestimento/antiaderente, descobriu-se que o processo de fabricação da Panelas NA estava mais ajustado para utilizar insumo fornecido por outra fornecedora, a empresa Revestimento DP. A utilização do produto fornecido pela Revestimento WW obrigaria a Panelas NA a realizar ajustes no processo, pois a temperatura de polimerização do revestimento estava acima da capacidade do forno destinado a esta atividade.

O disco de alumínio fornecido pela Alumínio CA não possibilitava a obtenção de uma superfície apropriada ao processo de revestimento. A utilização de material reciclado dificultava o preparo da superfície do disco para aplicação do antiaderente.

As entrevistas realizadas revelaram o desconforto do fornecedor da Revestimento WW. A inadequação do insumo fornecido pela WW deu origem a uma crise no relacionamento entre os agentes, em especial, quando a informação "vazou" para o mercado. Diante desse cenário, a WW passou a refutar os resultados, retirando-se do projeto, pois entendia que a imagem da empresa estava sendo prejudicada. Esta posição culminou com a substituição desse fornecedor pela empresa Revestimento DP.

Da mesma forma, a Alumínio CA foi substituída pela Alumínio NV. Como a Alumínio CA reconhecia suas restrições, a sua eliminação do processo não estabeleceu uma crise entre as partes.

Nesse momento, o aprofundamento do conhecimento do processo produtivo por todas as partes deixou transparentes competências e habilidades. A objetividade expressa de modo especial nos relatórios técnicos evidenciou incompatibilidades no processo, derivadas de inadequações dos fornecedores Alumínio CA e Revestimento WW. O processo não reforçou as expectativas sobre as competências e habilidades desses parceiros (pelo menos no que se refere às necessidades do projeto). Ao contrário, deixou evidente que a oferta dos fornecedores CA e WW não era compatível, o que demandaria esforços e investimentos adicionais, provocando distintas reações dos dois fornecedores: um absorveu essa transparência o outro não.

Assim, a aquisição do conhecimento do processo como um todo redundou na transparência das competências técnicas dos agentes, mas o resultado não foi a emergência da confiança no expertise dos parceiros.

\section{Análise e discussão dos resultados}

$\mathrm{O}$ início do processo de relacionamento da empresa cliente com seus fornecedores tem como marcas a ausência de ligações/informações técnicas e a evidente manifestação, por parte das empresas fornecedoras, do risco quanto à transferência de conhecimento nuclear, constitutivo do denominado "segredo de processo". Destaca-se que a empresa matriz também tinha receio em aprofundar o relacionamento com os fornecedores.

Na fase exploratória e na fase de constituição do grupo multiempresas, cada agente conhecia somente seu processo, não detendo informações do conjunto das atividades da cadeia produtiva. Acrescenta-se que os membros do grupo possuíam uma história bastante limitada de trabalho em conjunto. Em síntese, predominava o desconhecimento de formas de trabalhar de maneira interdependente e a reduzida confiança entre os agentes.

Como não existiam ligações entre os agentes, a Eletrodomésticos AR (empresa cliente) assumiu o papel de agente estruturador e coordenador (das relações). Nessa direção, ao instituir regras e procedimentos de coordenação das atividades desenvolvidas em conjunto, o agente coordenador estabeleceu uma espécie de pacto entre os membros do grupo, sem, no entanto, eliminar integralmente as dificuldades de acesso às informações.

O estabelecimento de padrões formais de conduta no interior do grupo multiempresas se consubstanciou na:

- Regularidade (frequência) de contatos entre os seus membros, visando definir ações, compartilhar decisões e resultados;

- Definição de mecanismos formais de comunicação - relatórios técnicos; e

- Definição de padrões técnicos para a realização dos ensaios (testes).

Sobressai, ademais, a criação de uma linguagem padronizada (procedimentos padrões de controle da qualidade) e o desenvolvimento de uma metodologia de pesquisa comum, baseada em testes, conectando problemas ou sintomas a causas específicas.

O sistema formal de controle/coordenação - sistema de gestão da qualidade - configurou um conjunto de códigos, interfaces, rotinas e linguagens comuns, que constituiu a base de resolução dos problemas conjuntos e, de modo especial, funcionou para estabelecer um quadro de referência das relações entre os agentes.

De acordo com a linha teórica, centrada nas propostas de Tomkins (2001), Dekker (2004) e Vosselman e Meer-Kooistra (2004 e 2009), a definição das regras de funcionamento do acordo atuou como um importante sinal para os diferentes parceiros, aumentando a previsibilidade de seu comportamento. O hábito de trabalhar em conjunto favoreceu a construção da confiança mútua, na direção da "boa vontade em compartilhar informações". Ao definir regras e procedimentos de atuação, o sistema de gestão da qualidade criou um ambiente de transparência no comportamento dos agentes, deixando explícitos os seus interesses.

Apesar do receio das empresas fornecedoras, o aumento da frequência dos ensaios técnicos e das 
reuniões levou à maior proximidade na relação entre os agentes, o que facilitou a aquisição e a transferência do conhecimento tácito. Isso não significou, no entanto, que foi consolidada a disposição efetiva a cooperar. Em contraste com o arcabouço teórico, os novos padrões de conduta só foram efetivos, em um primeiro momento, para criar um contexto favorável à emergência do goodwill. Isto é, considerando os antecedentes do relacionamento (desconhecimento do processo como um todo e risco de transferência de informações), os agentes conseguiram aprender a trabalhar juntos, a compartilhar informações e, de modo especial, a deixar transparentes os seus interesses.

$\mathrm{Na}$ verdade, a introdução de procedimentos formais de controle na gestão da qualidade, ao deixar transparentes as competências técnicas dos agentes, acabou redundando em uma situação de conflito, a partir da reação daqueles fornecedores que viram a sua expertise colocada em xeque. Assim, a transparência das competências e habilidades dos parceiros emerge como o elemento decisivo para definição do aporte de recursos dos parceiros. Na medida em que a expectativa for positiva, o aporte de recursos gera uma confiança efetiva, capaz de sustentar o projeto cooperativo. Caso contrário, dá origem ao conflito.

Como se percebe, a constituição do grupo multiempresas funcionou, para a empresa cliente, como um momento de negociação e, em especial, de revelação do comportamento, das habilidades e do conhecimento técnico dos fornecedores. Foi um longo processo de testes e de provas. Note-se que foi bastante difícil para as empresas fornecedoras disponibilizarem o conjunto de informações sob seu controle. A situação de forte assimetria de informação encorajava comportamentos oportunistas. No entanto, a introdução de sistemas formais de controle, patrocinados pela empresa cliente, atuou como elemento-chave na direção de tornar acessíveis as informações e, de modo especial, o conhecimento técnico.

\section{Conclusão}

O presente estudo analisou as relações entre empresas que demandavam a troca de conhecimento tecnológico e de processo de fabricação, em um contexto marcado pelo desconhecimento entre as partes, pelo conflito e pela desconfiança.

Ficou evidenciado, em primeiro lugar, que o critério inicial para definição dos insumos e do processo, baseado em pressupostos eminentemente de natureza financeira (menor custo), se mostrou inadequado, pois não considerou a complexidade do processo de resolução conjunta de problemas. Uma proposta de fornecimento técnico não sustentada na troca de informações e de conhecimento mostrou-se inadequada, implicando em altos custos de rejeição de produtos e insumos inadequados.

Em segundo lugar, na constituição de um grupo composto por agentes das diferentes organizações envolvidas (cliente e fornecedoras) foi imperativa a instituição de procedimentos formais de controle e coordenação. Esses procedimentos permitiram contextualizar o campo das interações entre os agentes, derivando daí duas consequências fundamentais. De um lado, imprimiu foco e direção ao grupo, por meio da definição dos insumos/variáveis relevantes e da delimitação de responsabilidades. De outro, possibilitou a criação de um espaço de explicitação de interesses e de transparência das habilidades técnicas dos parceiros.

Nesse sentido, o estudo aponta para a importância da introdução do sistema formal de controle/coordenação na fase inicial da relação cliente-fornecedor para:

- Instituir fluxos de comunicação entre os agentes e padrões mínimos de relacionamento; e

- Revelar o conhecimento técnico detido pelos agentes.

Com relação à hipótese central colocada, que afirma a existência do nexo entre o sistema formal de controle e a confiança nessa fase crítica do relacionamento cliente- fornecedor, não foi integralmente comprovada.

Embora se buscasse a confiança baseada na competência técnica, pois todos os agentes não conheciam profundamente o processo produtivo como um todo, os padrões formais de conduta somente derivaram em um "clima de confiança", ao que tudo indica, baseado eminentemente no goodwill. Quando ocorreu o aprofundamento da interação que permitiu o refinamento do conhecimento mútuo (a efetiva e objetiva avaliação da habilidade técnica dos parceiros), a transparência e a consolidação das informações técnicas acabou por abalar o goodwill (boa vontade) por parte de um dos parceiros. $\mathrm{O}$ resultado foi o conflito, resultando na sua retirada do arranjo.

Fica evidente que a dimensão objetiva da confiança, que se expressa na competência técnica e na necessidade de efetivar investimentos específicos a ela atrelados, constitui uma espécie de "prova de fogo" para avaliar o real comprometimento dos agentes à relação. Não se trata de boa vontade, mas do aporte de recursos e da revelação do grau de conhecimento técnico. O foco não é a acomodação de interesses conflitantes, mas a integração efetiva das contribuições individuais. A confiança baseada na competência (habilidade) é fundamental para a consolidação de um arranjo interorganizacional, na medida em que condiciona a inserção de cada parceiro no conjunto de atividades e orienta a sua expectativa com relação à importância da sua colaboração.

Em síntese, esse estudo se coloca como complementar à linha teórica liderada por Tomkins, Dekker e Vosselman e Meer-Kooistra. O nexo identificado no 
caso estudado entre o sistema formal de controle e o aumento do goodwill provavelmente está associado ao tipo e à forma de implementação dos procedimentos formais de controle. Mais precisamente, a opção por determinados procedimentos de controle assim como a intenção subjacente podem ser eficientes para sustentar determinado tipo de confiança e não outro.

É ilustrativo a esse respeito lembrar que, no caso em foco, a marca inicial da relação foram os aspectos eminentemente financeiros e os de natureza emocional, deixando-se para o segundo plano o grau de ajustamento a um conjunto pré-determinado de atributos associados a especificações técnicas.

Com a mudança do enfoque da relação, a partir da iniciativa da empresa cliente, o sistema formal de controle por ela patrocinado foi orientado por procedimentos eminentemente técnicos. A empresa cliente passou a privilegiar o aprofundamento do conhecimento para atuar no segmento de panelas com antiaderente e, em um contexto de fortes resistências por parte das empresas fornecedoras, os referidos procedimentos foram fundamentais para possibilitar o acesso às informações técnicas. A Eletrodomésticos AR passou a deter um elevado conhecimento das variáveis do processo, permitindo-lhe especificar os controles necessários à obtenção de um produto de qualidade.

Assim, a seleção da metodologia de ciclo PDCA como procedimento de controle e a intenção subjacente acabaram por transformar (no momento da prova de fogo), como não poderia deixar de ser, face aos antecedentes, o sistema formal de controle/ coordenação em fonte de conflito e não de cooperação. Tal fato tem a ver com a ausência de uma avaliação preliminar da capacidade técnica dos agentes no processo de seleção dos fornecedores. A inclusão de agentes que não atendem a requisitos técnicos, a despeito da boa vontade e da demonstração de interesse na relação, não deixa espaço para a emergência da confiança na habilidade dos parceiros. Nessa direção, não é que o sistema de controle não favoreça a emergência da confiança, mas sim que a ausência de uma base técnica na relação impede o avanço da cooperação e, mais ainda, deriva na desestabilização da confiança assentada no goodwill. Esse é um ponto a ser aprofundado em futuras pesquisas.

Abrem-se novas oportunidades de pesquisa, voltadas ao aprofundamento da análise da interação entre controle/coordenação nas fases maduras do relacionamento, em especial, em situações marcadas pela introdução de mudanças (novos produtos e novos processos) e, em consequência, incertezas.

Outro campo de análise é a influência do "grau de assimetria" existente na relação entre os agentes sobre a instituição de procedimentos formais de coordenação e controle. A presença de um líder, ocupando uma posição dominante, com considerável grau de hierarquização, seria uma condição para a implementação e efetividade da formalização ou, ao contrário, a situação caracterizada pela simetria de poder, isto é, pela ausência de um agente centralmente posicionado, seria mais favorável.

\section{Referências}

BHIMANI, A. A study of the emergence of management accounting system ethos and its influence on perceived system success. Accounting, organizations and society, v. 28 , n. 6, p. 523-546, 2003. http://dx.doi.org/10.1016/ S0361-3682(02)00025-9

BREI, V. A. Construção da confiança em trocas relacionais de serviço: uma pesquisa nacional com usuários de Internet. In: ENCONTRO DA ASSOCIAÇÃO NACIONAL DOS PROGRAMAS DE PÓS-GRADUAÇÃO EM ADMINISTRAÇÃO - ENANPAD, 27., 2003, Curitiba. Anais... Curitiba: Anpad, 2003. Disponível em <http://www.anpad.org.br/enanpad/2003/dwn/ enanpad2003-mkt-1189.pdf>. Acesso em: 30 jun. 2010.

BSTIELER, L. Trust Formation in Collaborative New Product Development. Journal of Product Innovation Management, v. 23, n. 1, p. 56-72, 2006. http://dx.doi. org/10.1111/j.1540-5885.2005.00181.x

COLETTI, A. L.; SEDATOLE, K. L.; TOWRY, K. L. The effect of control systems on trust and cooperation in collaborative environments. The Accounting Review, v. 80, n. 2, p. 477-500, 2005. http://dx.doi.org/10.2308/ accr.2005.80.2.477

COOPER, R.; SLAGMULDER, R. Interorganizational cost management and relational context. Accounting, organizations and society, v. 29, n. 1, p. 1-26, 2004. http://dx.doi.org/10.1016/S0361-3682(03)00020-5

DAS, T. K.; TENG, B. S. Trust, control and risk in strategic alliances: An integrative framework. Organization Studies, v. 22, n. 2, p. 251-283, 2001. http://dx.doi. org/10.1177/0170840601222004

DEKKER, H. C. Control of inter-organizational relationships: Evidence on appropriation concerns and co-ordination requirements. Accounting, Organizations and Society, v. 29, n. 1, p.27-49, 2004. http://dx.doi.org/10.1016/ S0361-3682(02)00056-9

DE WEVER, S.; MARTENS, R.; VANDENBEMPT, K. The impact of trust on strategic resource acquisition through interorganizational networks: Towards a conceptual model. Human Relations, v. 58, n. 12, p. 1523 1543, 2005. http://dx.doi.org/10.1177/0018726705061316

EISENHARDT, K. Building Theories from case study research. Academy of Management Review, v. 14, n. 4, p. 532-550, 1989 .

GUMMESSON, E. Qualitative methods in management research. Newbury Park:Sage Publications, 2000.

HERNANDEZ, J. M. C.; SANTOS, C. C. Proposta para um modelo de mensuração de confiança entre canais de marketing. In: ENCONTRO DA ASSOCIAÇÃO NACIONAL DOS PROGRAMAS DE PÓS-GRADUAÇÃO EM ADMINISTRAÇÃO - ENANPAD, 31., 2007, Rio de Janeiro. Anais... Rio de Janeiro: Anpad, 2007.

KAMMINGA, P. E.; MEER-KOOISTRA, J. van der. Management control patterns in joint venture 
relationships: A model and an exploratory study. Accounting, Organizations and Society, v. 32, n. 1-2, 131-154, 2007. http://dx.doi.org/10.1016/j. aos.2006.03.002

KNIGHTS, D.; NOBLE, F.; VURDUBAKIS, T.; WILlMOTT, H. Chasing shadows: Control, virtuality and the production of trust. Organization Studies, v. 22, n. 2, p. 11-336, 2001. http://dx.doi. org/10.1177/0170840601222006

LANGFIELD-SMITH, K.; SMITH, D. Management control systems and trust in outsourcing relationships. Management Accounting Research, v. 14, n. 3, p. 281-307, 2003. http://dx.doi.org/10.1016/ S1044-5005(03)00046-5

LANGLEY, A. Strategies for theorizing from process data. Academy of Management Review, v. 24, n. 4, p. 691-710, 1999.

MAYER, R. C.; DAVIS, J. H.; SCHOORMAN, F. D. An integrative model of organizational trust. Academy of Management Review, v. 20, n. 3, p. 709-734, 1995.

MEER-KOOISTRA, J. van der; VOSSELMAN, E., Management control of inter-firm transactional relationships: the case of industrial renovation and maintenance. Accounting, Organizations and Society, v. 25 , n. 1, p. 51-77, 2000. http://dx.doi.org/10.1016/ S0361-3682(99)00021-5

MINTZBERG, H. The Structuring of Organizations. Englewwod Cliffs: Prentice Hall, 1979.

NESS, H. Interorganizational developmental process: governance and interaction in continuous negotiated agreements. 2001. Thesis (Ph.D.)-Norwgian School of Economics and Business Administration, Helleveien, 2001. Disponível em: <http://scholar. google.com.br/scholar?q=Interorganizational+develop mental+process $\% 3 \mathrm{~A}+$ governance+and+interaction $+\mathrm{I}+$ continuous+negotiated+agre $>$. Acessoem: 25 jun. 10.

NEWELL, S.; SWAN, J. Trust and inter-organizational networking. Human Relations, v. 53, n. 10, p. 1287-1328, 2000.

NOOTEBOOM, B. Trust, opportunism and governance: a process and control model. Organization Studies, v. 17 , n. 6 , p. 985-1010, 1996. http://dx.doi. org/10.1177/017084069601700605

OUCHI, W. G.; MAGUIRE, M. A. Organisational control; two functions. Administrative Science Quarterly, v. 20, n. 4, p. 559-569, 1975. http://dx.doi.org/10.2307/2392023

POPPO, L.; ZENGER, T. Do formal contracts and relational governance function as substitutes or complements? Strategic Management Journal, v. 23, n. 8, p. 707-725, 2002. http://dx.doi.org/10.1002/smj.249
ROWE, C.; BIRNBERG, J. G.; SHIELDS, M. D. Effects of organizational process change on responsibility accounting and managers' revelations of private knowledge. Accounting, Organizations and Society, v. 33, n. 2-3, p. 164-198, 2008. http://dx.doi.org/10.1016/j. aos.2006.12.002

SMITH, K. G.; CARROLL, S. J.; ASHFORD, S. J. Intra and interorganizational cooperation: towards a research agenda. Academy of Management Review, v. 38, n. 1, 7-23, 1995. http://dx.doi.org/10.2307/256726

SOUZA, A. C.; RIBEIRO, C. M.; PRADO, P. H. M. Um estudo sobre os Relacionamentos Organizacionais do Tipo buyer-seller entre Operadoras de Planos de Saúde e Prestadores de Serviços em Saúde. In: ENCONTRO DA ASSOCIAÇÃO NACIONAL DOS PROGRAMAS DE PÓS-GRADUAÇÃO EM ADMINISTRAÇÃO ENANPAD, 32., 2008, Rio de Janeiro. Anais... Rio de Janeiro: Anpad, 2008.

SZULANSKI, G. Exploring internal stickiness: impediments to the transfer of best practice within the firm. Strategic Management Journal, v. 17, Winter Special Issue, p. 27-43, 1996.

TOMKINS, C. Interdependencies, trust and information in relationships, alliances and networks. Accounting, Organizations and Society, v. 26, n. 2, p. 161-191, 2001. http://dx.doi.org/10.1016/S0361-3682(00)00018-0

VÉLEZ, M. L.; SÁNCHEZ, J. M.; ÁLVAREZ-DARDET, C. Management control systems as inter-organizational trust builders in evolving relationships: Evidence from a longitudinal case study. Accounting, Organizations and Society, v. 33, n. 7-8, p. 968-994, 2008.

VLAAR, P. W. L; BOSCH, F. A. J. van den; VOLBERDA, H. W. Coping with Problems of Understanding in Interorganizational Relationships: Using Formalization as a Means to Make Sense. Organization Studies. v. 27, n. 11, p. 1617-1638, 2006. http://dx.doi. org/10.1177/0170840606068338

VOSSELMAN, E.; MEER-KOOISTRA, J. van der. Accounting for the alignment of interest and commitment in interfirm transactional relationships. 2004. ERS-2004095-F\&A. p.1- 25.

VOSSELMAN, E.; MEER-KOOISTRA, J. van der. Accounting for control and trust building in interfirm transactional relationships. Accounting, Organizations and Society, v. 34, n. 2, p. 267-283, 2009. http://dx.doi. org/10.1016/j.aos.2008.04.002

YIN, R. K. Estudo de caso: planejamento e métodos. 4. ed. Tradução de Ana Thorell. Porto Alegre: Bookman, 2010. WHYTE, W. F. Participatory action research. Newbury Parck: Sage, 1991 
